\title{
A SMART APPLICATION FOR VEHICLE AUTOMATION DEALING WITH TRAFFIC REGULATIONS AND AIR POLLUTION FOR ENVIRONMENT
}

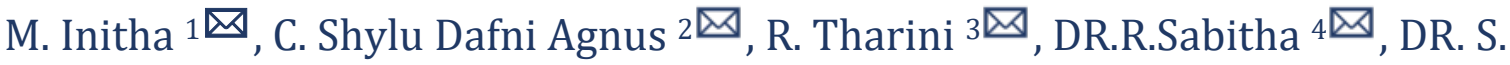 \\ Sivaranjani 5
}

1, 2,3 Department of Computer Science and Engineering, Avinashilingam Institute for Home Science and, Higher Education for Women School of Engineering, Coimbatore, India

${ }^{4}$ Associate professor, Department of Computer Science and Engineering, Avinashilingam Institute for Home Science and Higher Education for Women School of Engineering, Coimbatore, India ${ }^{5}$ Assistant professor, Department of Computer Science and Engineering, Avinashilingam Institute for Home Science and Higher Education for Women School of Engineering, Coimbatore, India

DOI: https://doi.org/10.29121/granthaalayah.v8.i5.2020.61

Article Type: Research Article

Article Citation: M. Initha, C. Shylu Dafni Agnus, R. Tharini, DR.R. Sabitha, and DR. S. Sivaranjani. (2020). A SMART APPLICATION FOR VEHICLE AUTOMATION DEALING WITH TRAFFIC REGULATIONS AND AIR POLLUTION FOR ENVIRONMENT. International Journal of Research GRANTHAALAYAH, 8(5), 194-198. https://doi.org/10.29121/granthaa layah.v8.i5.2020.61

Received Date: 08 May 2020

Accepted Date: 31 May 2020

Keywords:

Mobile Detection

Signboards

Accident Prone

Voice Alert

LCD Display

RFID Reader

RFID Tag

Gas Sensor

\section{ABSTRACT}

Transportation has evolved greatly in recent years. With the modern Technologies, the automobile industry has obtained new heights with the respect to speed, efficiency and security. Despite growth and improvement in technology there has been rise in the rate of accidents. The technology used in the proposed design is embedded system. It is used to access, process, store and control the data. Now-a-day's traffic rules are frequently violated by the drivers and over speeding occur due to bad driving behaviour. It may not be possible to view the regulatory (sign) boards placed by the Road safety Department to alert the drivers in such kind of places and there is a chance for accident. The main objective of the Project is to design and develop a new system that can effectively detect speed violations on the road, and support the driver to obey traffic rules while driving by maintaining the speed of vehicle in accordance to the speed limit prescribed for the particular zone. The proposed system gives an alert with the help of voice module and LCD. The main objective of the project is to overcome the challenges which include accidents that occur due to lack of concentration, conversing over phone while driving and the pollution emitted by the vehicles. 


\section{INTRODUCTION}

The road accidents are the major cause for pre-mature death and disability from the past few decades. As per the survey of the World Health Organisation (WHO), nearly 1.3 million people are losing their lives in the accidents, every year more than 50 million people get injured. The numeral count of the accidents are increasing due to the over speed, negligent driving, poor vicinity of roads, using mobile phones while driving, etc.,

Among the following reasons over speed, poor vicinity and mobile phone usage play a significant role in major accidents not only for the drivers but also for the pedestrians. To reduce the count of the accidents the Government are also taking a respective steps like Sign boards, speed humps etc.., but the individual riders doesn't pay attention to the sign boards sometimes they are least bothered about the sign boards.

So, the necessity to design a smart system to alert the riders about the sign boards to reduce the count of the accidents and to send the alert about mobile phone usage. There are various methods available for designing a system. But this paper deals with two methods namely RFID reader, RFID tags for identify the sign boards like school zone, speed limit, and mobile detector sensors for mobile phone usage.

Along with this the vehicular pollution also plays a major role in environment, with increase in the population, there is an increase in number of vehicles. This leads to various health and the environmental issues. This project also deals with the pollution control in the vehicles by using the Gas sensor to detect the pollution level which can be taken into a note.

\section{RELATED WORKS}

An application for accident using block chain-based incentive mechanism. Application that can be used for the accident zone. This system uses GPS technology for location tracking and sends an alert message about the accident. The generated accident alert message send to the nearby registered users who also witness the accident. [1]

Accident Detection System using IOT. The healthcare industry is working to reduce the accident in urban areas with the help of IOT technology with accurate communication. This paper can detect the accident immediately and alert about the emergency [2].

Obstacle detection and accident prevention Using Radio Frequency for the smart zone. This paper describes about the speed of the vehicle in the particular geo fenced zone, every time by receiving the signal of radio waves the speed of the vehicle is controlled [3].

The system for monitoring and controlling the driver behaviour and usage of the mobile phone while driving. In this paper the GPS is used for tracking the speed of the vehicle and this diagnostic the mobile usage by the drivers. The information regarding the behaviour of the driver is also noticed [4].

Smart Phone Detection for driver detection. In this paper the ubiquitous camera feature of mobile phones is used to detect the position of the camera. It enables the drivers to detect the phones without rely on any situations, particular events and hard devices. [5]

Mobile phone usage and distraction detection of drivers using smart phones. To get the information, the sensors in phones can be used to detect about the people who drive the car. The technology of new smart phone consists of lots of sensors which can be used for the future work [6].

Monitoring the quality of air by using wireless sensor network. In this the temperature, humidity, volume of carbon monoxide, volume of carbon dioxide in the environment are monitored. It can also be used to detect the smoke particles. The values are transmitted through Bluetooth so that the person can check it through the mobile phones. [7]

Air pollution detection using wireless sensor network. The wireless sensor network can be applicable only by using internet. It can be able to monitor nitrous oxide, humidity, carbon monoxide. The routing algorithm which is used in the pollution detection is Mobile Ad Hoc Network. It covers the area of 300 meters around the city. The vehicles will send the sensor data to the drivers to monitor the pollution effectively. [8]

Mobile sensing for vehicle air quality monitoring. Carbon monoxide, carbon dioxide and other harmful gases emitted by the vehicles can lead to health problems. The vehicle indoor air quality is sensed by the mobile to detect and understand the change. It is built by using the smart phones and mobile sensor. It is applicable for any car models. 
Vehicular air pollution detection in automated control system. When the emitted level of pollution is beyond the threshold level there will indication about the limit and the vehicle will be stop after the certain period of time. During this period the GPS will start locating the nearest service station. The entire process is controlled and monitored by a microcontroller.

\section{PROPOSED SYSTEM}

The proposed system is developed for the pedestrians and also the diver safety to reduce the accidents. The sign board detection system is designed using RFID tags and RFID reader. To reduce the accident level and to safe lives of the pedestrians, the system is developed. The system comes to play in flagitious situations especially due to the lack of concentration in night rides.

The usage of mobile phones while driving also plays a major role in accidents, to reduce the level of accidents and to alert the drivers this system is used. The mobile detector sensor is used to detect the usage of the mobile phones. The Voice modules are given to alert the drivers.

The last module of the proposed system is to control the vehicluar pollution. The gas sensor (MQ-135) is used to calculate the emitted level of the gas particles. The emitted gas particles are taken in to account so that it can be reduced.

The block diagram is shown below in figure 1.

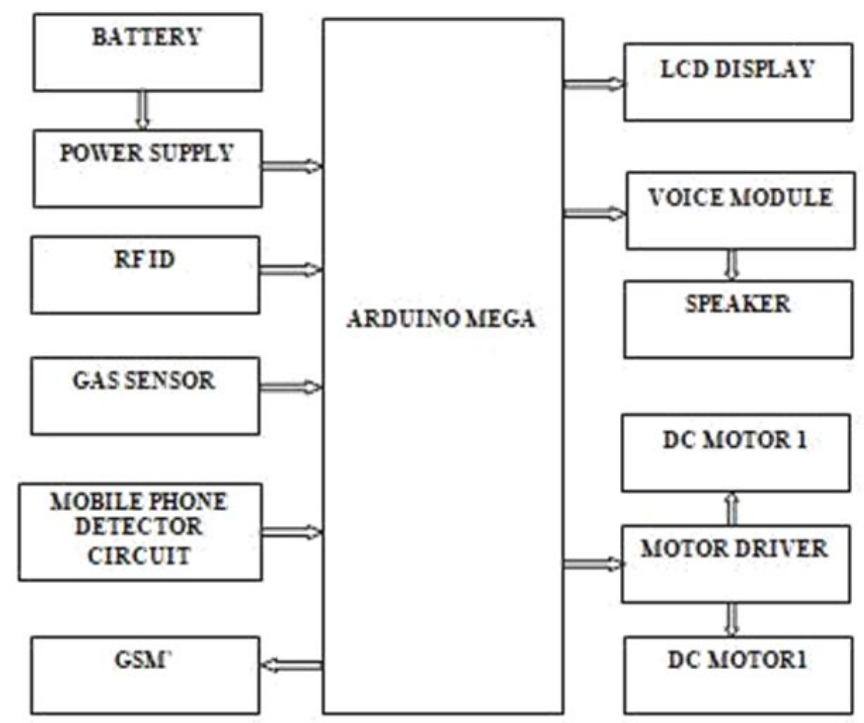

Figure 1: Block diagram

\section{MODULE DESCRIPTON}

\subsection{REQUIREMENT ANALYSIS}

The hardware required for the development of the prototype is discussed, here the user interface play a significant role to get the successful implementation of the product. The developing prototype should be user friendly.

\subsection{IMPLYING RFID TAGS AND RFID READER}

The RFID tag in this project helps to sense the sign boards and the regulatory boards on the roads. The RFID readers is used to read the tags placed on the boards to alert the driver about the upcoming boards. This is the major module which helps to detect the Exact location of the sign and regulatory boards. 


\subsection{ALERT INCEPTION OF POLLUTION}

The calculated amount of pollution by the gas sensor is taken into account, so that the user can be given with the alert message regarding the pollution level to the registered number.

\subsection{MOBILE DETECTION}

The mobile phone detector is used to detect the usage of phones while driving. This module is to check that the driver is accessing the mobile while driving.

\subsection{CONNECTING THROUGH GSM}

Based on the endorsement of the alert message, the initiator may transmit an alert message to the nearby emergency services.

\subsection{SPEED CONTROLLER}

The speed of the vehicle is controlled and regulated by the motors. This controlling mechanism uses the motor reversing and line breaking of the vehicle. The speed limit is also taken into the consideration.

\section{WORKING PRINCIPLE}

The proposed system is based on three units. We check for the regulatory boards on the roads and the alert is given with the voice module with the help of the speaker to the drivers in prior (500m ahead). The boards are fitted with the RFID tags, so that with the help of the RFID reader the boards can be sensed. The sensed data of the sign boards are fetched by the RFID reader and that is given to the voice module then for the speaker to alert the drivers. The RFID reader scans the tags on the boards so that the information can be noted,

Due to the usage of mobile phones while driving accidents occurs a lot. By using the Mobile Detector device and the mobile phone magnet the usage is noted. The mobile phone magnet consists of the circuit which includes the opamp for the inverting and non-inverting signals. The incoming and the outgoing signals from the mobile phone even in the silent mode is taken in has the input in the op-amp and the signal is given to the ardunio. The ardunio mega is connected with the DC motors so if the system detects the usage of phones the speed of the vehicles is controlled, and further it continues the vehicle is automatically stops, with the voice message.

Due to the increase in the level of pollution emitted by the vehicles it causes health problems and environmental issues. By using the MQ-135 gas sensor we deduct the level of the pollution. The emitted level of the pollution is noted and that is displayed in the LED for the user reference. If the level of the pollution is beyond the threshold level the message will be send to the registered number through GSM.

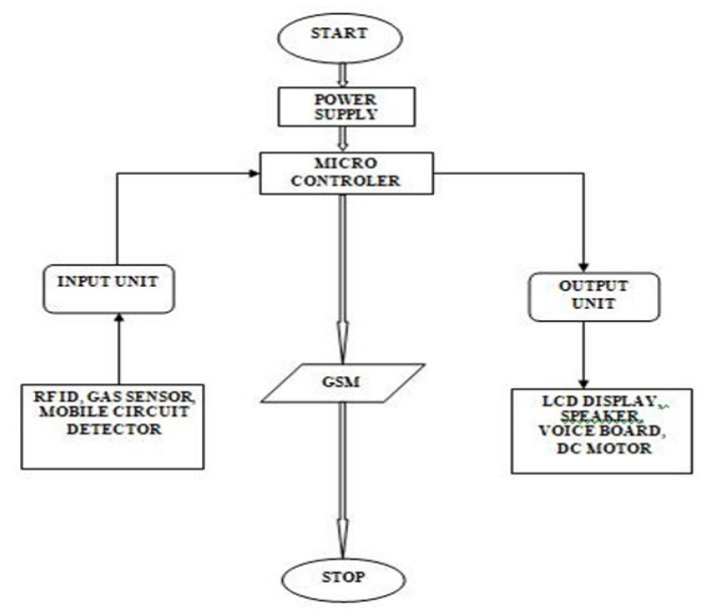

Figure2: flowchart 
The power supply is given to the micro controller. The microcontroller can be powered via the USB connection or with an external power supply. The RFID and the mobile circuit detector are the two inputs which are given to the microcontroller. The Arduino mega is connected with the GSM. The LCD display, speaker, voice board and DC motor are the output units which are connected to the microcontroller.

\section{CONCLUSION}

This project is applicable on current system. It needs low value and sturdy, permits most safety to passengers and public, the drivers get all data concerning the road with none distraction whereas driving even in weather condition conditions, low power consumption. The mobile detector circuit is employed to detect the usage of phones so that the driver can focus on the roads. This project is additional increased by automatic speed management once the vehicles get any hazard signal from outside surroundings. A prototype model of controller is made on the speed control capability. Drivers can get the data regarding the condition of the roads at previous. The sign board of varied zones (school zone, hospital zone, "U" flip zone etc) is detected by the RFID tag and therefore the information are scanned by the RFID reader. They successively, put together to control the speed of car wheels. This design with success utilizes a brand-new plan of hybrid vehicle recently immerged in automotive trade. The system doesn't need a physical braking system which is able to cut back the value of an automotive.

\section{SOURCES OF FUNDING}

None.

\section{CONFLICT OF INTEREST}

None.

\section{ACKNOWLEDGMENT}

None.

\section{REFERENCES}

[1] Saulsgiver, K.A.; Lee, Y.C. Attitudes on technological, social, and behavioural economic strategies to reduce cell phone use among teens while driving. Traffic Inj. Prev. 2018, 19, 569-576. [CrossRef] [PubMed]

[2] Vennela Priyadarshni, P. Gopi Krishna, K. Sreenivasa Ravi, "GPS and GSM Enabled Embedded Vehicle Speed Limiting Device”, Indian Journal of Scince \& Technology, Vol 9(17), May 2016

[3] P Gurusamy, M Anusha, N Devipriya, P Harini, MD AsrarUlHaque C, "Speed Control of Vehicle by Detection of Potholes and Humps", IJAREEIE, Vol 5, 1-2 March 2016.

[4] Kassem, N. Microsoft Corp., Redmond, WA, USA Kosba, A.E.; Youssef, M.; VRF-Based Vehicle Detection and Speed Estimation vehicular Technology Conference (VTC Spring), IEEE (2012).

[5] Kassem, N. Microsoft Corp., Redmond, WA, USA Kosba, A.E.; Yousuf, M.; VRF-Based Vehicle Detection and Speed Estimation vehicular Technology Conference (V TC Spring), IEEE (2012).

[6] Gangadhar, S.; R N shetty Inst. Of Techno, intelligent road traffic Control system, IEEE conference Publication, kahargpur (2010).

[7] Telaprolu, M.K, sarma, V.V. ratankanth, E.K. Rao, SN. Banda, vehicular Electronics and safety (ICVES), IEEE International Conference pune (2009).

[8] Berndt, Don, Real-Time Embedded Technology and Applications Symposium (RTAS), IEEE Education \& Learning (2005). 